\title{
Impact Assessment of Offshore Pile Driving Noise on Red Sea Marine Mammals
}

\author{
Waled A. Dawoud, Abdelazim M. Negm, Nasser M. Saleh, and Mahmoud F. Bady
}

\begin{abstract}
Red Sea is one of the most important repositories of the marine biodiversity in the world. Red Sea oil and gas reserves are estimated to be around 100 billion barrel of oil equivalent necistate the use of offshore structure to extract it. Most of offshore drilling rigs and production platforms are found on group of large diameter piles which are driving into sea bed producing high amount of underwater noise. Underwater noise emitted during pile construction can mask biologically relevant signals for marine mammals. This noise might lead to behavioral reactions, harassment, and at very high levels can injure or even kill the mammal. Range-dependent Acoustic Model, Rogers Model, was used to assess underwater noise propagation of offshore pile driving taking into account seabed bathymetry, temperature, and salinity. It was found that an offshore pile driven with $235 \mathrm{~kJ}$ rated energy diesel hammer can cause behavioral disturbance to the marine mammal within a distance of $1000 \mathrm{~m}$ from the pile location; temporary threshold shift within a distance of $30 \mathrm{~m}$; permanent threshold shift within a distance of $50 \mathrm{~m}$; and injury, or even death, within a distance of $20 \mathrm{~m}$.
\end{abstract}

Index Terms-Red sea marine mammals, pile driving noise, underwater noise propagation, threshold levels, rogers model.

\section{INTRODUCTION}

Red Sea is one of the most important repositories of the marine biodiversity in the world, it support populations for many species of marine mammals (about 15 species of dolphins and whales, and one dugong species). Red Sea Governorate tourism industry, which depends mainly on marinewildlife and recreation tourism, contributed significantly to the Egyptian economy in 2003 to reach about $10 \%$ of GDP and $4 \%$ of total employment [1]. At the same time, Red Sea oil and gas reserves are estimated to be around 100 billion barrel of oil equivalent. Kingdom of Saudi Arabia is planning to employ 200 drilling rigs in 2014 most of it will be in the Red Sea [2] which, in the absence of proper environmental studies, will affect significantly the Red-Sea eco-system.

Manuscript received October 30, 2014; revised April 28, 2015. This work was supported by Egyptian Ministry of Higher Education (MoHE) as a Ph.D. scholarship.

W. A. Dawoud is with Environmental Engineering Department, School of Energy and Environmental Engineering, Egypt-Japan University of Science and Technology (E-JUST), New Borg Al-Arab City, Postal Code 21934, Alexandria, Egypt (e-mail: walid.dawoud@ejust.edu.eg).

A. M. Negm is with Environmental Engineering Department, School of Energy and Environmental Engineering, E-JUST, Seconded from Zagazig University, Egypt (e-mail: negm@ejust.edu.eg, amnegm85@yahoo.com).

N. M. Saleh is with Faculty of Engineering at Shoubra, Benha University, Egypt (e-mail: na_sa_64@hotmail.com).

M. F. Bady is with Environmental Engineering Department, School of Energy and Environmental Engineering, E-JUST, Seconded from Assiut University, Egypt (e-mail: mahmoud.bady@ejust.edu.eg).
Most of offshore drilling rigs and production platforms are found on group of large diameter piles which are driving into sea bed. During pile driving; extremely high sound levels are produced in both the surrounding air and underwater environment. In terms of the underwater environment, field observations show peak acoustic pressures of $1.0 \mathrm{kPa}$ measured at a range of $3000 \mathrm{~m} \mathrm{[3]}$, around $10 \mathrm{kPa}$ measured at a range of $60 \mathrm{~m} \mathrm{[4],} \mathrm{and} \mathrm{around} 100 \mathrm{kPa}$ measured at a range of $10 \mathrm{~m} \mathrm{[5]} \mathrm{from} \mathrm{the} \mathrm{pile} \mathrm{driving} \mathrm{operation.} \mathrm{Such}$ pressures are known to produce deleterious effects on both fish and marine mammals [6].

Underwater noise effects on marine mammals are of particular interest because marine mammals has a wide distribution area in the coastal waters of the Red Sea, acute hearing, and functional hearing over a very wide frequency range [7]-[10]. Marine mammals are relatively easily deterred by anthropogenic underwater noises [11]. Avoidance threshold levels of harbor porpoises have been determined for noise bands and tonal signals around $12 \mathrm{kHz}$, a continuous $50 \mathrm{kHz}$ tone, and continuous and pulsed 70 and $120 \mathrm{kHz}$ tones [12]. Reference [11] studied the effects of underwater noise on marine mammals from driving $4.0 \mathrm{~m}$ diameter steel mono-pile foundations for offshore wind turbines in the North Sea (Source Level $235 \mathrm{~dB}$ re $1 \mu$ Pap-p at $1 \mathrm{~m}$ ), by quantifying their echo-location activity. Reduced echo-location activity occurred at over $21.0 \mathrm{~km}$ from the pile driving site. Reference[13] reported that offshore pile driving sounds reduced detected marine mammals acoustic signals at distances of up to $18 \mathrm{~km}$ from the sound source. Based on visual surveys and static acoustic monitoring; reference [14] reported strong avoidance within $20 \mathrm{~km}$, reduced echo-location at distances less than $11 \mathrm{~km}$, and increased detection rates at 25 and $50 \mathrm{~km}$ from the pile driving source.

Although the importance of Red Sea biodiversity to the Egyptian economy and the world ecosystem; no attempt has been made to investigate the propagation of underwater noise and its effects on Red Sea ecosystem. The goal of the present study is to assess the effects and extends of offshore pile driving noise on marine mammals in the Red Sea taking into account sea bottom bathymetry, temperature, and salinity using range-dependent underwater propagation empirical model (Rogers Model).

\section{RED SEA ECOSYSTEM}

Red Sea marine ecosystem is considered tropical and semi-enclosed extending from Suez and Aqaba gulf in the north to the strait of Bab-Elmandeb in the south with width ranges from 30 to $280 \mathrm{~km}$ as shown in Fig. 1. Red Sea is considered an environmentally unique area in terms of circulation, temperature and salinity with warm clear waters 
and a complex reef ecosystem which provides habitats for a wide range of marine species. There are over 1100 species of fish (whereof about 40 are endemic). There are more than 200 species of corals, species, 125 of which are soft corals, 40 species of star fish, 25 species of sea urchins, more than a 100 species of mollusks and 150 species of crustaceans in the Red Sea [15].

Red Sea support populations for about 15 species of dolphins and whales, and one dugong species [16]. Seven mammal species have been resident for a long time: the Bottlenose Dolphin, Bryde's Whale, Indopacific Bottlenose Dolphin, Pantropical Spotted Dolphin, Longbeaked Common Dolphin, Risso's Dolphin and the Spinner Dolphin. Recently Humpback Dolphins, whose normal habitat is the east coast of Africa, have also been seen in the Red Sea [17].

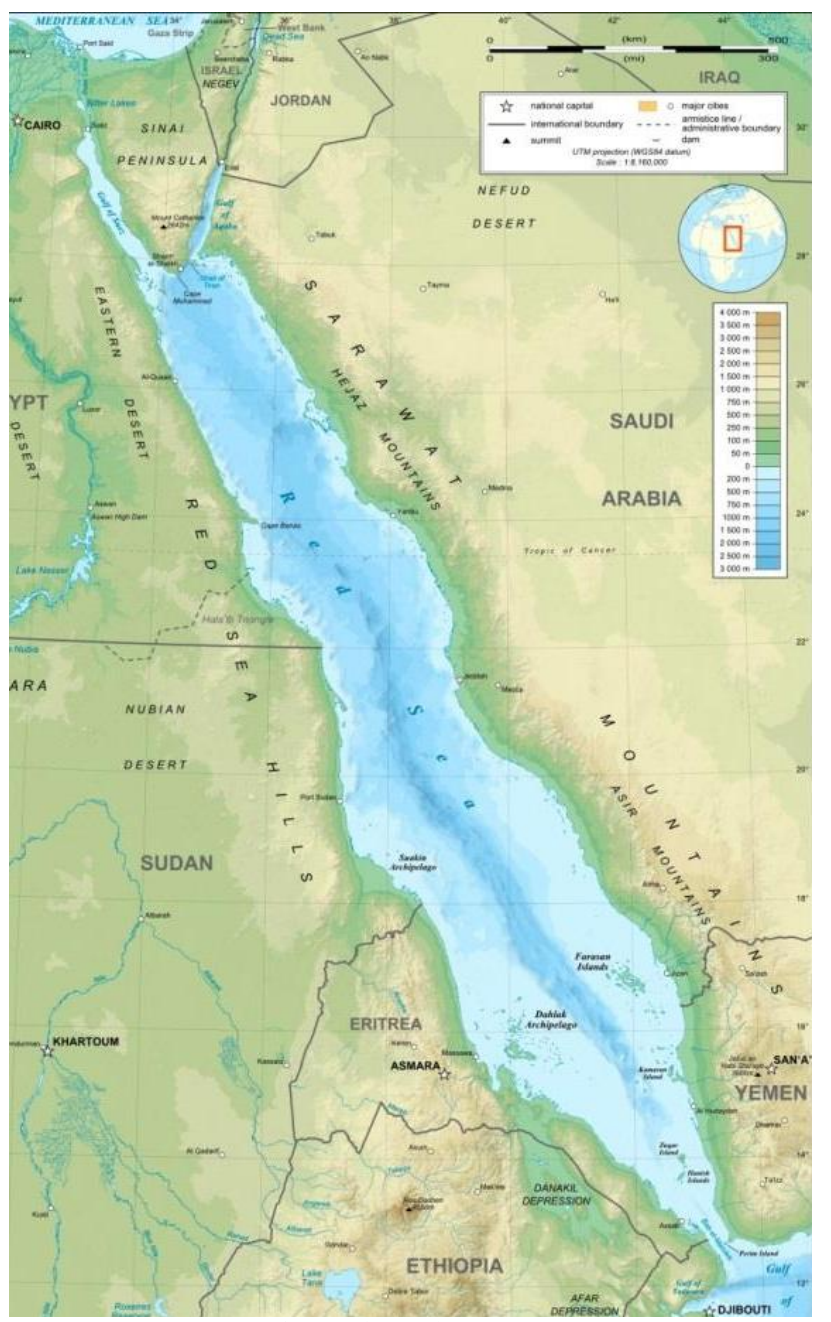

Fig. 1. The Red Sea [18].

\section{UNDERWATER NOISE}

\section{A. Pile Driving Underwater Noise}

Four types of mechanical waves are produced during pile driving namely: Compressional, Shear, Rayleigh, and Lowe waves. Only compressional waves need to be considered when studying noise effects on marine mammals because its ability to travel in water [19]. Based on generation conditions; sound waves can be divided into plane and spherical waves. In ideal medium; plane waves can propagate with no energy loss in contrast to spherical waves which follow spherical law energy decay.
Sound waves propagation in water differs than in air in many aspects; Sound waves in water have a pressure 60 times larger (and a displacement amplitude 60 times less) than that in the air because of the difference in acoustic impedance. Also the air/water interface acts as sound reflector (Lloyd's mirror) therefore sound generated underwater waves will not pass over the air and it will be reflected with an opposite polarity.

\section{B. Underwater Sound Propagation Models}

The understanding of underwater sound propagation is the key to understand and predict all other underwater acoustic phenomena. Different sound propagation models were developed since the World War II [20] which can be divided, based on its theoretical approach, as in Fig. 2.

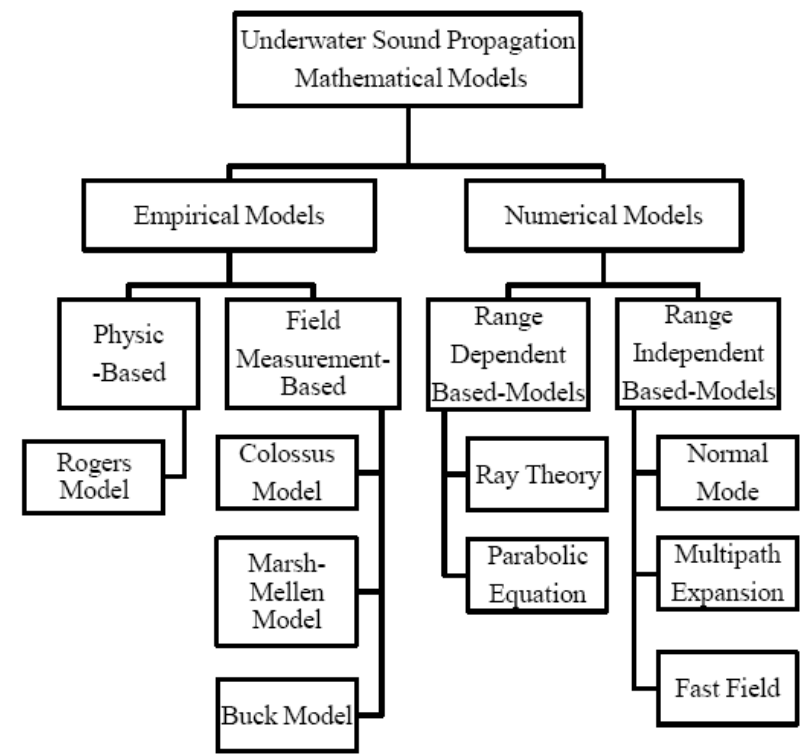

Fig. 2. Underwater sound propagation mathematical models.

Any sound propagation model should take into account transmission losses (TL) of sound waves. The decay rate of sound waves propagate underwater depends mainly on sound frequency, sound source depth, water temperature, water salinity, water depth, and sea bed conditions. The use of sophisticated models may lead to misleading results due to limited knowledge of subsurface conditions. Simplified empirical models can give a better estimate of the variation in sound wave with distance which is enough for the preliminary assessment of the pile driving noise impacts on marine mammals.

\section{Rogers Model}

Rogers model was used to predict transmission losses of underwater sound waves since 1981 [20]. The model was derived bases on theoretical approach (physics-based) assuming that all shallow water transmission losses, for negative sound speed gradient, can be described by the following equation:

$$
T L=15 \log _{10}^{R}+5 \log _{10}^{(H \beta)}+\frac{\beta R \theta_{L}^{2}}{4 H}+\alpha_{w} R-7.18
$$

where $R$ is the range (m), $H$ the water depth (m), $\beta$ the bottom loss $\left(\mathrm{dB} \operatorname{rad}^{-1}\right), \theta_{L}$ the limiting angle $(\mathrm{rad})$, and $\alpha_{w}$ the absorption coefficient of sea water.

The bottom loss $\left.(\beta \mathrm{dB} \mathrm{rad})^{-1}\right)$ can be approximated, for small limiting angles $\left(\theta_{L}\right)$, as follows: 


$$
\beta \approx \frac{0.477 M_{0} N_{0} k_{S}}{\left[1-N_{0}^{2}\right]^{3 / 2}}
$$

where $N_{0}=c_{w} / c_{s}, c_{w}$ is the maximum (sea surface) sound speed $\left(\mathrm{ms}^{-1}\right)$ and $c_{s}$ is the sound speed $\left(\mathrm{ms}^{-1}\right)$ in the sediments; $M_{0}=$ $\rho_{\mathrm{s}} / \rho_{w}, \rho_{w}$ is the density of sea water and $\rho_{s}$ is the sediment density and $K_{s}$ the sediment attenuation coefficient $\left(\mathrm{dBm}^{-1}\right.$ $\mathrm{kHz}^{-1}$ ).

Numerous empirical methods, based on laboratory and field measurements, were developed to predict sound speed in water. A simplified formula was given in [21] as follows:

$$
\begin{aligned}
& C=1449.2+4.6 T-0.055 T^{2}+0.00029 T^{3} \\
& \quad+(1.34-0.01 T)(S-35)+0.016 H
\end{aligned}
$$

where $T$ is the temperature $\left({ }^{\circ} \mathrm{c}\right), \mathrm{S}$ is the salinity (PPT), and $\mathrm{H}$ is the depth $(\mathrm{m})$.

The limiting angles $\left(\theta_{L}\right)$ is the larger of the maximum grazing angle for a skip distance $\left(\theta_{g}\right)$ and the effective plane-wave angle corresponding to the lowest propagating mode $\left(\theta_{c}\right)$ as follows:

$$
\begin{gathered}
\boldsymbol{\theta}_{\boldsymbol{g}}=\sqrt{\frac{2 \boldsymbol{H g}}{C_{W}}}(\mathrm{rad}) \\
\boldsymbol{\theta}_{\boldsymbol{c}}=\frac{\boldsymbol{C}_{w}}{2 \boldsymbol{2 \boldsymbol { H }}}(\mathrm{rad})
\end{gathered}
$$

where $g$ is the magnitude of the negative sound-speed gradient $\left(\mathrm{s}^{-1}\right)$, and $f$ is the frequency $(\mathrm{Hz})$.

\section{Noise Effects on Marine Mammals}

The potential for underwater noise to affect marine mammals depends on how well the animal can hear the noise. Noises which can't be heard by the mammal are less likely to disturb or injure them except when it is associated with high sound pressure that can causes physical injury [22]. Marine mammals can be divided based on its functional hearing to the groups shown in Table I [22]:

TABLE I: FUNCTIONAL HEARING GROUPS

\begin{tabular}{lc}
\hline \hline & Estimated auditory bandwidth \\
Functional hearing group & $(\mathrm{kHz})$ \\
\hline Low-frequency cetaceans & $0.007-22$ \\
Mid-frequency cetaceans & $0.150-160$ \\
High-frequency cetaceans & $0.200-180$ \\
Pinnipeds in water & $0.075-75$ \\
Pinnipeds in air & $0.075-30$ \\
\hline \hline
\end{tabular}

Marine mammals have different hearing at different frequencies within their functional hearing range; frequency weighting is used to quantitatively compensating for the difference in frequency response based on mammal's audiograms [23]. Two metrics are commonly used to describe sound parameters: sound pressure level (SPL) and sound exposure level (SEL). SPL is the maximum sound pressure at any given moment produced by a particular activity measured in $\mathrm{dB}$ re: $1 \mu \mathrm{Pa}$. SEL is a measure of energy exposure level measured in $\mathrm{dB}$ re: $1 \mu \mathrm{Pa}^{2} \mathrm{~s}$. The main difference between these two parameters is that SPL can be an instantaneous value and SEL is the total noise energy to which the mammal is exposed during a given duration, typically one second for pulse sources [24]. Because pile driving is an ongoing impulsive activity that will occur throughout the construction phase; sound exposure level shall be used.

To assess the impact of underwater noise on Red Sea

\begin{tabular}{|c|c|c|c|c|}
\hline Methodology & $\begin{array}{l}\text { Death/ } \\
\text { Injury } \\
\text { (SPL) }\end{array}$ & $\begin{array}{c}\text { Permanent } \\
\text { Threshold } \\
\text { Shift (SEL) }\end{array}$ & $\begin{array}{l}\text { Temporary } \\
\text { Threshold } \\
\text { Shift (SEL) }\end{array}$ & $\begin{array}{c}\text { Behavioral } \\
\text { Response } \\
\text { (SEL) }\end{array}$ \\
\hline Dolphins & $>200$ & $>178-198$ & $>183$ & $>120-150$ \\
\hline Whales & $>200$ & > 178-198 & $>183$ & $>120-180$ \\
\hline Dugongs & $>200$ & $>178-198$ & $>183$ & $>120-150$ \\
\hline
\end{tabular}
marine mammals, the marine mammals shall be divided into three main categories; Dolphins Whales, and Dugongs. The SEL threshold levels (in $\mathrm{dB}$ re: $1 \mu \mathrm{Pa}^{2} \mathrm{~s}$ ) and SPL (in $\mathrm{dB}$ re: 1 $\mu \mathrm{Pa})$ for these categories are shown in Table II [23]:

\section{MATERIALS AND METHOD}

\section{A. Assessment Procedure}

The following procedures were used to assess the impact of pile driving noise on marine mammals in the red sea. The procedures given in Fig. 3 can be used at any location in the red sea with any pile configuration.

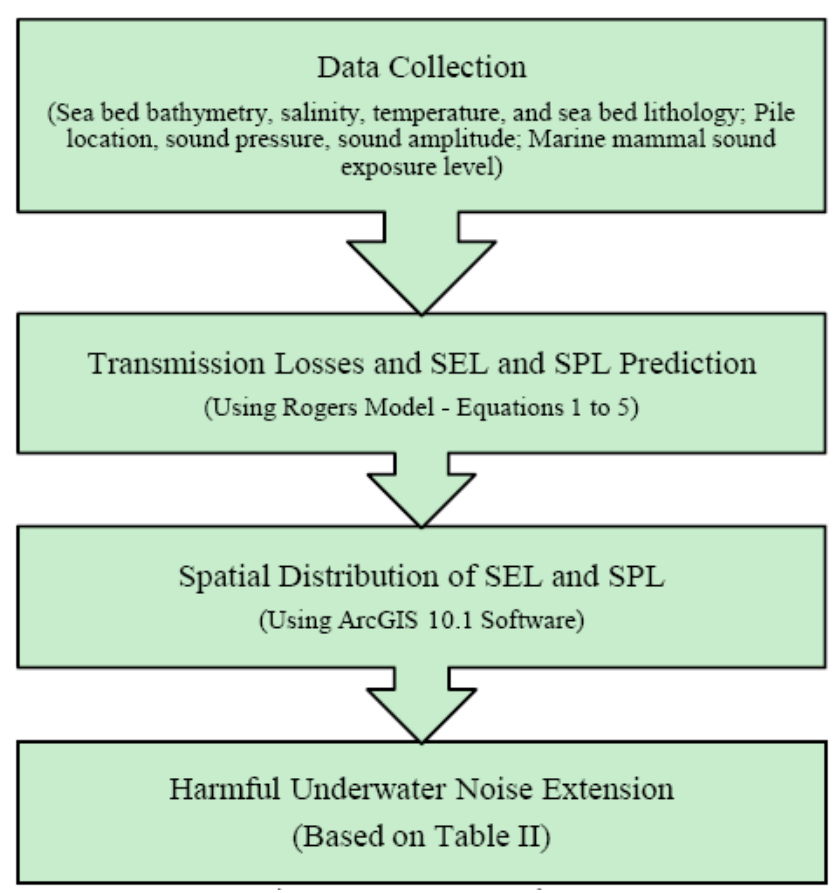

Fig. 3. Assessment procedure.

\section{B. Red Sea Bathymetry, Salinity, and Temperature Profile}

The red sea bathymetry was attained from National Oceanic and Atmospheric administration [25] with $4 \mathrm{~km}$ resolution. The data then gradually resampled into a maximum resolution of $100 \mathrm{~m}$ around the pile location using beam bathymetry survey data attained from [26] as shown in Fig. 4. An area around the pile location $18 \times 18 \mathrm{~km}^{2}$ was then resampled into $10.0 \mathrm{~m}$ resolution using Natural-Neighbor interpolation.

The salinity and temperature data in Red Sea were extracted from National Oceanic and Atmospheric administration [25] location of the observation stations is shown in Fig. 5a). Using the salinity and temperature 
observations data; salinity and temperature profiles were created as shown in Fig. 5b) and Fig. 5c).

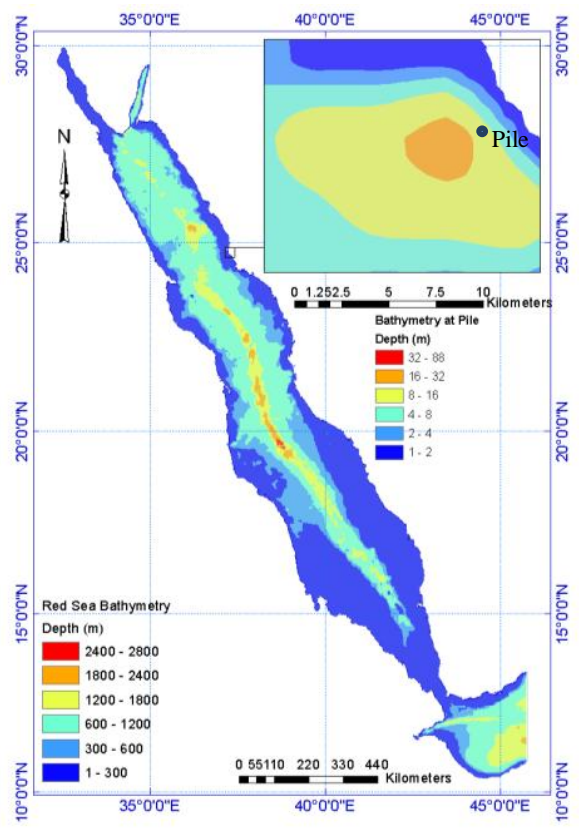

Fig. 4. Red Sea bathymetry.

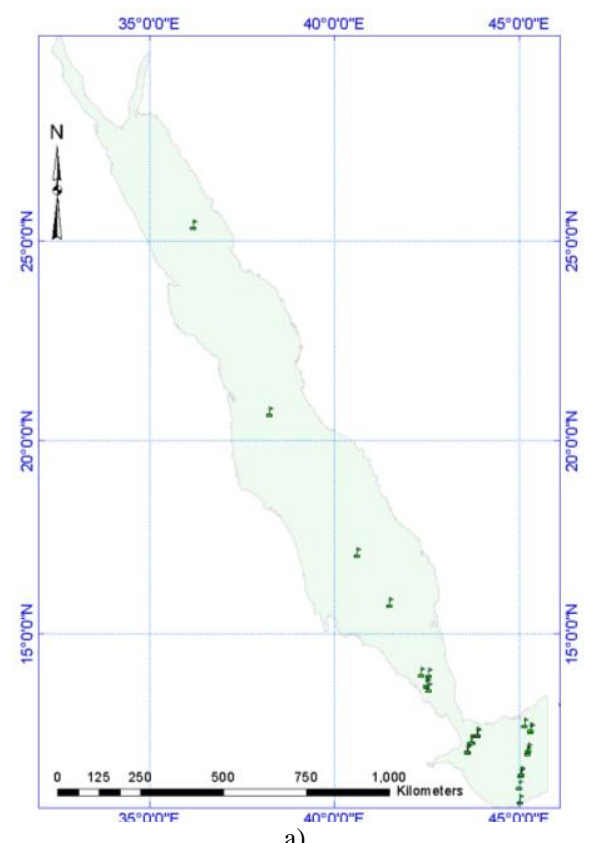

a)
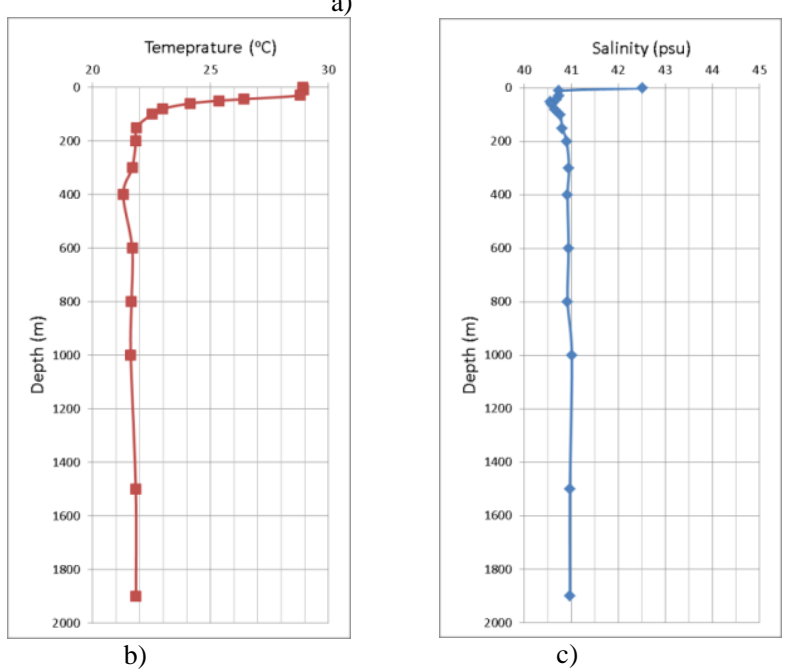

Fig. 5. a) Observation stations, b) Temperature profile, and c) Salinity profile.

\section{Pile Characteristics}

The study was made to be consistent with one of the 136 piles constructed to support ship repair yard along Jeddah coast, Saudi Arabia [27]; a hollow steel pile, approximately $96 \mathrm{~m}$ long with $1.40 \mathrm{~m}$ diameter and wall thickness of $1.9 \mathrm{~cm}$. The pile was driven approximately $80 \mathrm{~m}$ into the sediment in water $16.0 \mathrm{~m}$ deep [28]. The piles were driven with a Kobe-80 Diesel Hammer with ram weight of $78.5 \mathrm{kN}$ and energy of $235 \mathrm{~kJ}$. No cushion between the ram and pile was used. The sound source level from the $235 \mathrm{~kJ}$ hammer was predicted by assuming the underwater noise output of a pile strike is proportional to the energy delivered to the pile as in (6):

$$
\Delta B_{0}=10 \log _{10}\left(\frac{E}{E r}\right)
$$

The reference sound source level was for the $49 \mathrm{~kJ}$ diesel hammer proposed in [23]. Table III shows the reference source levels and the predicted source levels for the $235 \mathrm{~kJ}$ hammer.

TABLE III: REFERENCE AND PREDICTED SOURCE LEVELS (AT 1.0 M)

\begin{tabular}{lcc}
\hline \hline Hammer Energy & SEL & SPL \\
& $\left(\mathrm{dB} \mathrm{re} 1 \mu \mathrm{Pa}^{2} . \mathrm{s}\right)$ & $(\mathrm{dB}$ re $1 \mu \mathrm{Pa})$ \\
\hline $49 \mathrm{~kJ}$ & 199 & 213 \\
$235 \mathrm{~kJ}$ & 205.8 & 219.8 \\
\hline \hline
\end{tabular}

\section{Sea Bed Lithology}

The sea bed lithological profile near the studied site reveal that it contains mainly from the following geologic units [28]:

1) Heterogeneous surface layer consists of coral, coral debris, clays, sands and silts formed during the Pleistocene till present.

2) Gravels and sands of igneousorigin formed during the Pleistocene.

3) Siltstone, clays, claystone, limestone, gypsum formed during the Pliocene.

Fig. 6 shows the generalized geologic cross-section as given by [28].

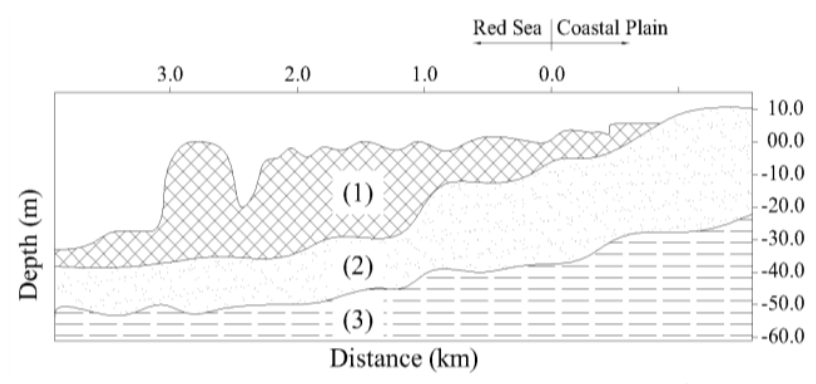

Fig. 6. Geological cross-section near the site, reproduced from [28].

\section{E. SEL and SPL Prediction}

The transmission losses (TL) were calculated at each point using equations 1 to 5. SEL and SPL are then calculated using the following formula:

$$
\begin{gathered}
S E L_{i}=S E L_{o}-T L_{i} \\
S P L_{i}=S P L_{o}-T L_{i}
\end{gathered}
$$

where $S E L_{i}$ is the sound exposure level at point $i, S E L_{o}$ is the 
sound exposure level at source, $S P L_{i}$ is the sound pressure level at point $i, S P L_{o}$ is the sound pressure level at source, and $T L_{i}$ is the transmission losses at point $i$.

\section{RESULTS}

The spatial distribution of the predicted sound exposure level (SEL) produced from driving the pile with a diesel hammer of $245 \mathrm{~kJ}$ rated energy is shown in Fig. 7. The SEL spatial distribution reveals that the underwater noise can propagate, with amplitude that can cause harm to the marine mammals, to a distance up to $1000 \mathrm{~m}$.

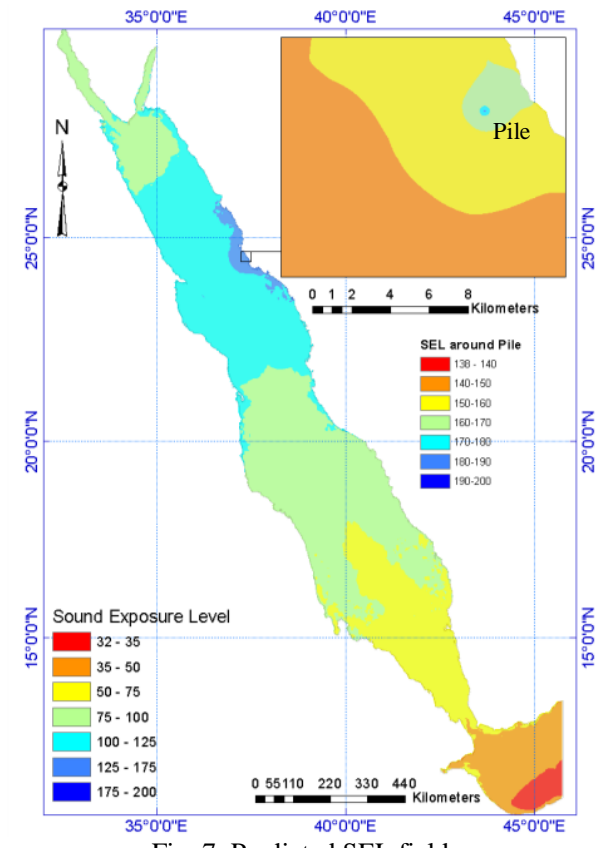

Fig. 7. Predicted SEL fields.

Fig. 8 shows the predicted sound pressure level (SPL) propagation around the pile location which shows that the marine mammal can be injured, or even killed, within a distance of $20.0 \mathrm{~m}$.

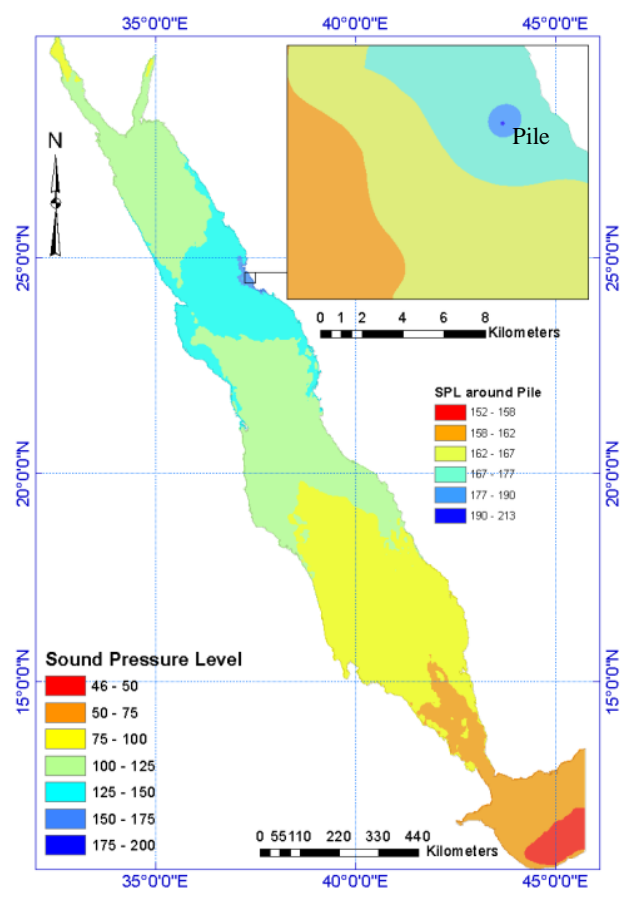

Fig. 8. Predicted SPL fields.

\section{CONCLUSION}

Range-dependent acoustic model, Rogers Model, was used to assess underwater noise propagation of $96 \mathrm{~m}$ offshore pile driven with Kobe-80 diesel hammer and constructed near Jeddah Coast, Saudi Arabia. Red Sea bathymetry, temperature, and salinity were taken into account in the model and it was found that:

1) The effect of sea water temperature and salinity has negligible effect on underwater sound propagation $(<0.01 \%)$.

2) The effect of red sea bathymetry has a minor effect on underwater sound propagation $(1.1 \%$.)

Pile with SEL $205.8\left(\mathrm{~dB}\right.$ re $\left.1 \mu \mathrm{Pa}^{2} . \mathrm{s}\right)$ and SPL of $219.8(\mathrm{~dB}$ re $1 \mu \mathrm{Pa}$ ) can cause the following

1) Behavioral disturbance to the marine mammal within a distance of $1000 \mathrm{~m}$ from the pile location.

2) Temporary threshold shift within a distance of $30.0 \mathrm{~m}$

3) Permanent threshold shift within a distance of $50.0 \mathrm{~m}$.

4) Injury, or even death, within a distance of $20.0 \mathrm{~m}$.

\section{ACKNOWLEDGMENT}

W. A. Dawoudis thankful to the Egyptian Ministry of Higher Education (MoHE) for funding his PhD studies. Also great thanking is due to Egypt-Japan University of Science and Technology (E-JUST) for offering the tools and equipment needed for the research.

\section{REFERENCES}

[1] G. Notarbartolo-di-Sciara, M. H. Hanafy, M. M. Fouda, A. Afifi, and M. Costa, "Spinner dolphin (Stenella longirostris) resting habitat in Samadai Reef (Egypt, Red Sea) protected through tourism management," J. Mar. Biol. Assoc. United Kingdom, vol. 89, no. 1, pp. 211-216, 2009.

[2] Oil service firms rush to Saudi for busy drilling year ahead. Reuters. (2014). [Online]. Available: http://uk.reuters.com/article/2013/10/27/aramco-rigs-idUKL5NOIF0V T20131027

[3] C. A. Jong and M. A. Ainslie, "Underwater radiated noise due to the piling for the Q7 offshore wind park," J. Acoust. Soc. Am., vol. 123, no. 5, p. 2987,2008

[4] S. P. Robinson, P. A. Lepper, and J. Ablitt, "The measurement of the underwater radiated noise from marine piling including characterisation of a 'soft start' period," OCEANS 2007 - Europe, 2007, pp. 1-6.

[5] P. Dahl, "An investigation of underwater sound propagation from pile driving," Wsdot. Wa. Gov., 2011.

[6] P. T. Madsen, M. Wahlberg, J. Tougaard, K. Lucke, and P. Tyack, "Wind turbine underwater noise and marine mammals: implications of current knowledge and data needs," Mar. Ecol. Prog. Ser., vol. 309, pp. 279-295, Mar. 2006.

[7] R. A. Kastelein, P. Bunskoek, M. Hagedoorn, W. W. L. Au, and D. Haan, "Audiogram of a harbor porpoise (Phocoena phocoena) measured with narrow-band frequency-modulated signals," J. Acoust. Soc. Am., vol. 112, no. 1, p. 334, 2002.

[8] R. A. Kastelein, P. J. Wensveen, L. Hoek, W. W. L. Au, J. M. Terhune, and C. A. F. Jong, "Critical ratios in harbor porpoises (Phocoena phocoena) for tonal signals between 0.315 and $150 \mathrm{kHz}$ in random Gaussian white noise.," J. Acoust. Soc. Am., vol. 126, no. 3, p. 1588, Sep. 2009.

[9] R. A. Kastelein, L. Hoek, C. A. F. de Jong, and P. J. Wensveen, "The effect of signal duration on the underwater detection thresholds of a harbor porpoise (Phocoena phocoena) for single frequency-modulated tonal signals between 0.25 and $160 \mathrm{kHz}$.," J. Acoust. Soc. Am., vol. 128, no. 5, pp. 3211-22, Nov. 2010.

[10] R. A. Kastelein, N. Steen, C. Jong, P. J. Wensveen, and W. C. Verboom, "Effect of broadband-noise masking on the behavioral response of a harbor porpoise (Phocoena phocoena) to 1-s duration 6-7 kHz sonar up-sweeps.," J. Acoust. Soc. Am., vol. 129, no. 4, pp. 2307-15, Apr. 2011. 
[11] J. Tougaard, J. Carstensen, J. Teilmann, H. Skov, and P. Rasmussen, "Pile driving zone of responsiveness extends beyond $20 \mathrm{~km}$ for harbor porpoises (Phocoena phocoena (L.))," J. Acoust. Soc. Am., vol. 126, no. 1, pp. 11-4, Jul. 2009.

[12] J. Carstensen, O. D. Henriksen, and J. Teilmann, "Impacts of offshore wind farm construction on harbour porpoises: acoustic monitoring of echolocation activity using porpoise detectors (T-PODs)," Mar. Ecol. Prog. Ser., vol. 321, pp. 295-308, 2006.

[13] M. J. Brandt, A. Diederichs, K. Betke, and G. Nehls, "Responses of harbour porpoises to pile driving at the Horns Rev II offshore wind farm in the Danish North Sea," Mar. Ecol. Prog. Ser., vol. 421, pp. 205-216, 2011.

[14] M. Dähne, A. Gilles, K. Lucke, V. Peschko, S. Adler, K. Krügel, J. Sundermeyer, and U. Siebert, "Effects of pile-driving on harbour porpoises (Phocoena phocoena) at the first offshore wind farm in Germany," Environ. Res. Lett., vol. 8, no. 2, p. 25002, 2013.

[15] (2014). Red sea marine life. [Online]. Available: http://www.aziab.com/red sea marine life.htm

[16] M. Sarhan, M. Hanafy, and M. Fouda, "Economics and sustainable use of samadai reef 'Dolphin House', Marsa Alam, Red Sea, Egypt," presented at Sixth International Bioecon Conference on Economics and the Analysis of Biology and Biodiversity, 2004.

[17] (2014). Marsa Alam Dolphins. [Online]. Available: http://www.marsaalam.com/Marsa_Alam_Dolphins.html

[18] (2014). Red Sea topographic map. [Online]. Available: http://upload.wikimedia.org/wikipedia/commons/1/19/Red_Sea_topo graphic_map-en.jpg

[19] G. Producers et al., "Fundamentals of underwater sound," 2008.

[20] P. C. Etter, Underwater Acoustic Modeling and Simulation, Abingdon, UK: Taylor \& Francis, 2003.

[21] H. Medwin and C. Clay, Fundamentals of Acoustical Oceanography, 1998.

[22] B. Southall, A. Bowles, and W. Ellison, "Marine mammal noise-exposure criteria: initial scientific recommendations," Bioacoustics, vol. 33, no. 4, 2008.

[23] P. Hedland, C. P. S. Kent, R. D. Mccauley, and A. J. Duncan, "Environmental impacts of underwater noise associated with harbour works," 2009.

[24] P. Theobald and P. Lepper, "Cumulative noise exposure assessment for marine mammals using sound exposure level as a metric," 2009.

[25] N. G. D. Center, Multibeam Bathymetric Data|ngdc.noaa.gov.

[26] Marine Environmental Data. (2014). [Online]. Available: http://www.niwa.co.nz/our-science/oceans/bathymetry/download-thedata

[27] W. Akili, "Driven pile foundation in coral sand, Jeddah, Saudi Arabia," in Proc. Int. Conf. Case Hist., no. 6, 1988.

[28] W. Akili, "Pile driving in coral deposits: A case study along the Red Sea," Geotech. Spec. Publ., pp. 604-618, 2002.

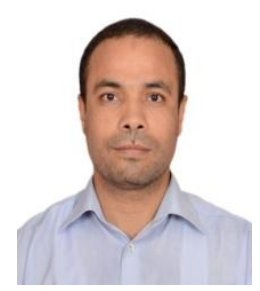

Waled A. Dawoud is a $\mathrm{PhD}$ student in Environmental Engineering Department, Egypt Japan University of Science and Technology. He was graduated from Faculty of Engineering at Shoubra, 2004 and from there he toke his M.Sc. in geotechnical Engineering. Through his master degree preparation period; he has gained good knowledge in different aspects of modelling ground water flow and underground structures using the finite element, finite difference, and boundary elements methods.

Through his major work in analysis and design of Mega Projects in Middle East, he obtained solid training in research, writing, and analysis. His main career interest lies in the analysis, and design of underground structures, marine structures, water and waste-water plants, and barrages. He has a good knowledge with programming languages like VB.net, Visual C++, C\#, and VBA in both Excel and AutoCAD. During his work, he gained a good experience in most of groundwater flow and geotechnical software.

Mr. Dawoudis a member in Egyptian Tunneling Society, Egyptian Soil Mechanics Society, and Egyptian Engineers Syndicate.

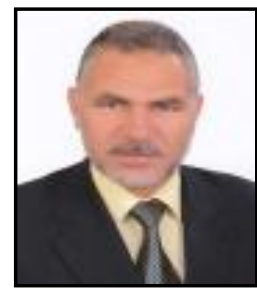

Abdelazim Negm was born in Sharkia, Egypt on April 16, 1962. He graduated in May 1985 from Zagazig University, Zagazig, Egypt and was awarded the B.Sc. degree in irrigation and environmental engineering with average grade very good with honors, with $84.5 \%$. Negm has been awarded the degree of master of science (M.Sc.) in civil engineering (irrigation and hydraulics) from Ain Shams University, Egypt and the $\mathrm{PhD}$ degree in hydraulics in 1992 from Zagazig University.

Currently, he is a professor of water resources in Egypt-Japan University for Science and Technology (E-JUST) since Oct. 1st, 2012 and the chairman of the Environmental Engineering Dept. at E-JUST since Feb. 17th, 2013. $\mathrm{He}$ worked as a demonstrator in the Faculty of Engineering, Zagazig University in 1986 and continued till he occupied the position of vice dean for Academic and Student Affair. He published about 220 papers in national and international Journals and conferences. He has awarded the prizes of best papers three times. His research areas include hydraulic, hydrology and water resources. Currently, he is very interested in the sustainability and green environment.

Prof. Negm is a member of IAHR and a member of the Egyptian permanent promotion committee for professorship promotion in field of water resources. He is a member of the editorial board of several scientific journals and a member of the organizing committee of IWTC18 and he is the secretary general of the conference as well.

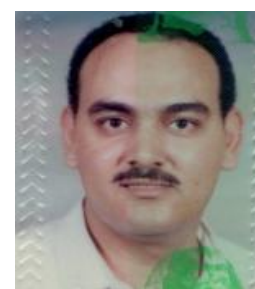

Mahmoud Bady was born in Assiut, Egypt on September 17, 1973 and graduated in June 1996 from Assiut University. He worked as a demonstrator in the Mechanical Engineering Department, Assiut University in 1996 and continued till he got the MSc degree in internal combustion engines in May 2002. Then he got his $\mathrm{PhD}$ in the field of air pollution modeling and control from University of Tokyo, Japan in September 2008. Currently, he is an assistant professor in Egypt-Japan University of Science and Technology (E-JUST) since September, 2011. He published about papers in national and international Journals and conferences in addition to three book chapters. He participated in more than 24 conferences. His research areas include air quality modeling, reverse simulation, wind energy, and meteorology. Dr. Bady is a member of famous academic organizations such as the Japanese Society of Heating, Air Conditioning and Sanitary Engineers (SHASE) and the Architecture Institute of Japan (AIJ). 